Revista Iberoamericana, Vol. LXXI, Núm. 212, Julio-Septiembre 2005, 711-729

\title{
LATINOUNIDENSES: IDENTIDAD, CULTURA, TEXTOS
}

\author{
POR \\ ELIANA RIVERO \\ Universidad de Arizona
}

Hace ya algunos años, se le preguntaba a cualquier persona de origen latinoamericano residente en los Estados Unidos cuál era su nacionalidad, y respondía sencillamente "peruano”, “puertorriqueña”, "guatemalteco”, “mexicana”, sin importar cuánto tiempo hubiese transcurrido desde su arribo a las playas del país, o en qué barrio de Nueva York, Los Ángeles, Chicago, Houston o Miami se hubiera criado o nacido. Hoy por hoy, la respuesta a esta pregunta es aparentemente más simple: “latino/a”. Digo aparentemente, porque durante una charla de la escritora Dolores Prida, la autora consultaba con el público: “¿qué puedo llamar sino latino al nieto de mi hermana, hijo de cubanoamericana y hondureño, nacido en Nueva York?” La dramaturga leía su ensayo inédito “Born-Again Latinos” en una plenaria de la conferencia Latina Letters, y después contestaba preguntas del público con respecto a cuestiones sobre particulares identidades hispánicas en los EE.UU. ${ }^{1}$ Prida argüía que el nombre Latino es necesario para designar al creciente número de hispano/latino/americanos de múltiple procedencia y herencia cultural.

Subyace una gran complejidad bajo ese calificativo, esa etiqueta. ¿Qué se implica con la palabra latino/a? ¿Desde cuándo nos sentimos los latinos parte integral de un conglomerado común que compone casi el doce por ciento de la población dentro de las fronteras de los Estados Unidos de Norteamérica?² ¿Cómo hemos transitado los caminos que nos han traído a la declaración general de ser latinos de los EE.UU. -latinounidensesy cómo se refleja este proceso en los textos literarios o culturales producidos en los últimos años? Desde los primeros intentos serios por definir la “conciencia étnica latina” (Padilla), hasta los más recientes estudios que proporcionan aproximaciones teóricas al término latino -señalando su potencial ahistórico aunque a la vez reconociendo su capacidad estratégica (Flores, "Pan-Latino/Trans-Latino...”)- el análisis de la(s) latinidad(es) se ha

\footnotetext{
${ }^{1}$ San Antonio, Tejas, julio 15 del 2001.

${ }^{2}$ Según las estadísticas del Buró del Censo (U.S. Census Bureau), en noviembre del año 2001 la población de origen hispano en los Estados Unidos casi alcanzaba los treinta y tres millones de individuos (las cifras dadas eran 32,832,000, o sea, el $11.9 \%$ de la población total de 276,059,000: http://eire.census.gov/popest/archives/national/nation3/intfile3-1.txt). Los cálculos ofrecidos por el Buró a principios del 2003, sin embargo, arrojan una cifra de más de treinta y siete millones para los latinos, que por primera vez (desde que se han recogido esas estadísticas) sobrepasan al número de afroamericanos en los EE.UU.
} 
atenido mayormente al campo de los estudios culturales, sociológicos y etnográficos (Rúa y Dávila), referidos frecuentemente a cierto subgrupo etnonacional presente en centros urbanos específicos (por ejemplo, Laó-Montes y Dávila, Mambo Montage: The Latinization of New York), pero siempre con un intento aclaratorio al tiempo que definitorio. Hay asimismo significativas exploraciones literarias más recientes (por ejemplo, William Luis y Flores, "Life Off the Hyphen”), y tal parece ser que el consenso estriba en matizar el término latino como controvertible si se considera su capacidad para homogeneizar experiencias históricas y oscurecer distinciones importantes entre poblaciones latinas de origen diverso (Rúa 118). No obstante, los términos latino y latina son utilizados regularmente como marcadores de etnoidentidad cultural múltiple referida a los grupos estadounidenses reconocibles por su conexión con culturas latinoamericanas de origen. ${ }^{3}$ En este ensayo, el uso de "latinounidense" conlleva una plena conciencia de todos los diversos matices teóricos y metodológicos, así como las problematizaciones, que el término latino ha suscitado.

Tanto en el aspecto anecdótico como en la labor creadora, muchos hay que se resisten a la agrupación panlatina ${ }^{4}$ en un solo bloque cultural, y reclaman su chicanidad o su cubanidad o su colombianismo contra viento y marea. Véase, por ejemplo, el semiburlesco y sin embargo serio comentario de Gustavo Pérez Firmat en su novela autobiográfica Next Year in Cuba:

...some of us Cubans, the younger ones, were actually born in this country. No longer the Cuban tribe, we're fast becoming part of the Latino community. We're making the difficult transition from exiles to ethnics. As an exile, I'm not sure I like it .... My trouble

\footnotetext{
${ }^{3}$ Unos de los primeros en anotar de manera sistemática el concepto de una comunidad cultural/ literaria latina en los EE.UU. fueron Marc Zimmerman en 1992 (véase su ensayo "U.S. Latinos: Their Culture and Literature”, como parte de su libro, en especial las páginas 9-44), Virgil Suárez y Delia Poey en su antología Iguana Dreams, también de 1992, y Frances Aparicio en Latino Voices, de 1994. En esos libros, igual que en otros ya a finales de la década de los noventa, se utiliza plenamente el término latinos en oposición a "hispanos". Una excepción posterior la constituyen Rodolfo Cortina e Ilan Stavans, quienes siguen empleando el segundo término después de 1996; hay que señalar que en Growing Up Latino (Augenbraum y Stavans, 1993) la introducción se refiere a los “U. S. Hispanics”, a pesar del título. En general, desde 1994 las antologías y estudios publicados parecen favorecer el término latino, alguno que otro no obstante conservando el comprensivo binomio de "hispanos/latinos", como el reciente volumen interdisciplinario editado por Gracia y De Greiff (ver la bibliografía de este artículo), y la antología de Lauro Flores, The Floating Borderlands (que contiene textos méxicoamericanos del siglo xix, entre otros). Para una genealogía de los términos, ver asimismo Oboler, Ethnic Labels, Latino Lives.

${ }^{4}$ Un considerable número de críticos culturales utiliza el término panlatino para designar la identidad múltiple del conglomerado de etnias latinas y su imaginario nacional en los EE.UU. (Flores, "Pan-Latino/Trans-Latino"). También se utilizan frases como "latinidad panétnica posnacional" ("postnational panethnic latinidad”: Knauer, "Eating in Cuban”, en Laó-Montes y Dávila, 442 ); "identidades panétnicas" ("panethnic identities”: Itzigsohn and Dore-Cabral, LaóMontes y Dávila, 333) y "población panétnica o pannacional” ("pannational” or "panethnic" population: Laó-Montes, introducción a Mambo Montage, 11). De ahí que nuestro uso de "panlatinidad", como se precisa en la nota 11, resulte menos complejo.
} 
is that I don't see myself as Latino, but as Cuban... to tell the truth, the Latino is a statistical fiction. Part hype and part hypothesis, the Latino exists principally for the purposes of politicians, ideologues, salsa singers, and Americans of non-Hispanic descent... (88)

No obstante la ironía del comentario citado, ${ }^{6}$ el término latino ha venido a ser mayormente aceptado en el ámbito nacional, tanto en los medios masivos de comunicación como en la literatura que describe el fenómeno cultural del mayor grupo minoritario de los Estados Unidos. ${ }^{7}$ Para algunos, el calificativo reflejaba al principio una conciencia política anti-asimilacionista que tenía su origen en organizaciones comunitarias, de forma similar a lo que los términos Chicano y Nuyorican expresaron en los sesenta y los setenta. ${ }^{8}$ A partir de los ochenta, hemos observado el uso, primero estratégico y después generalizado, de latino/a en los medios académicos (Abalos, Ortega y Sternbach, Zimmerman, Augenbraum,

5 “ ‘...algunos de nosotros, los más jóvenes, de hecho nacimos en este país. Ya no la tribu cubana, ahora nos estamos rápidamente convirtiendo en parte de la comunidad latina. Estamos en el proceso de transición entre exiliados y miembros de un grupo étnico. Como exiliado, no estoy seguro de que esto me guste. .... Mi problema es que yo no me veo como latino, sino como cubano.... a decir verdad, el latino es una ficción estadística. Parte publicidad sensacionalista y parte hipótesis, el latino existe principalmente para los propósitos de políticos, ideólogos, cantantes de salsa y americanos de ascendencia no-hispana....” (la versión en español es nuestra, así como también lo son otras traducciones del inglés en el texto y las notas de este artículo).

${ }^{6}$ Según Juan Flores, muchas personas consideradas “latinas" o "hispanas” le ponen objeciones a esas etiquetas, ofendiéndose ante lo que perciben como la confusión de su herencia personal e histórica con la de otros, y prefiriendo “designaciones nacionales" ("Introduction”, From Bomba to Hip-Hop, 7). De acuerdo a Itzigsohn y Dore-Cabral, en los espacios donde un grupo etnonacional es hegemónico en términos numéricos, económicos y/o políticos, dicho grupo tiende a rechazar la identidad latina panétnica (331).

7 Por otra parte, es común observar la expresión "Chicano/Latino", en descripciones sobre materiales, tópicos y estudios de los hasta hace poco denominados "hispanos". Por ejemplo, la colección "Chicanos/Latinos in the Movies" en la biblioteca de Berkeley, o "Chicano/Latino Films" en la Biblioteca de la Universidad de Stanford, según se puede leer en bibliografías digitalizadas, o "Chicano/Latino Studies" como denominación de departamentos y programas en muchos recintos universitarios, sobre todo en California: de hecho, cuando se realiza una búsqueda de la expresión “Chicano/Latino" en la Red Mundial, el cómputo de páginas electrónicas arroja más de mil quinientas, casi exclusivamente en referencias académicas. El doble término parece insinuar que los latinos son todos los otros hispanos estadounidenses no pertenecientes a la comunidad chicana, y podría producir confusiones (tal como las puede suscitar el muy utilizado binomio "Latinoamérica y el Caribe”, que a veces lleva a la pregunta: ¿ acaso no son latinoamericanos los caribeños?). Sobre esta aparente oposición binaria entre chicanos y latinos, ver Aparicio, "Reading the 'Latino'...., especialmente las páginas 7-8.

${ }^{8}$ Algunos textos poéticos tempranos del denominado "Chicano Reinassance" expresan ya en los sesenta y los setenta una visión panétnica que incluye a los grupos hispanos nacionales: "soy Mexican-American / soy American of Spanish surname (A.S.S.) /soy Latina/ soy Puerto Riqueña/ soy Cocoanut [sic]/ soy Chicana” (La Chrisx, "La Loca de la Raza Cósmica”, en Rebolledo y Rivero, 88). Arturo Madrid asegura, asimismo, que "los latinos empezaron a imaginarse a sí mismos como una unidad política panétnica hace más de tres décadas, durante el fervor de los sesenta” (10, "Imagining the U.S. Latino Community”; la traducción y el subrayado son nuestros). 
Aparicio, Latino Voices, Luis, Sandoval, José Can You See, Gracia y De Greiff). ${ }^{9}$ Sin embargo, la opinión popularizada de la mayoría anglosajona puede acogerse a cualquiera de los siguientes dos extremos: ya sea agrupando a los “hispanos”/latinos en un monolítico conglomerado de características estereotipadas, impuestas por una impresionista conclusión general sobre el carácter y naturaleza de "gentes de ascendencia mediterránea hispánica y/o mestiza"; ya sea dividiendo a los individuos a lo largo de líneas etnonacionales/raciales según sus diferentes países y culturas de origen, vagamente vislumbrados como pertenecientes a mundos diferentes, económica, política y culturalmente subdesarrollados. Por añadidura, la imaginación popular estima que las grandes masas de latinos residentes en los EE.UU. son inmigrantes (personas de piel oscura que han entrado -legal o ilegalmente- al país), haciendo caso omiso de las circunstancias históricas que crearon a los pueblos chicano y puertorriqueño, y desconociendo el desarrollo posmigratorio de las grandes comunidades latinoamericanas y sus descendientes en los estados de la Unión Norteamericana desde hace más de ciento cincuenta años. ${ }^{10}$

A pesar de las controversias, o precisamente a causa de ellas, este trabajo se propone interrogar la existencia de una construcción identitaria latinounidense general, o panlatinidad, ${ }^{11}$ mediante una lectura de textos significativos para la producción literaria de los “U.S. Latinos” en la última década. Este artículo insiste que, a pesar de las explícitas declaraciones de algunos autores y observadores, el latino no es en absoluto una ficción estadística ni un invento de los músicos salseros. Una cultura colectiva se encuentra en desarrollo, en parte producto de la agrupación involuntaria en que la mayoría anglosajona nos ubica, y ciertamente en parte debida a los medios masivos que, con fines de mercadeo, nos aglutina como consumidores de entretenimiento dirigido a la "teleaudiencia hispana/ latina” (como se nota en el desarrollo de las grandes cadenas televisivas Univisión o Telemundo). Este fenómeno, aunado a conexiones interlatinas propiciadas por el sistema educacional, los mercados laborales y alianzas tanto necesarias como inevitables en el ámbito social y demográfico, hacen de los latinounidenses un grupo que cada día sostiene más enlaces comunes (inclusive, por cierto, al nivel de conyugalidad), a medida que se configura y cimenta esa cultura translatina ${ }^{12}$ que, a causa de sus coordenadas de inmersión

\footnotetext{
${ }^{9}$ Un temprano uso del término se atribuye a declaraciones políticas como el manifiesto de los Young Lords, jóvenes radicales puertorriqueños en los EE.UU. (Luis 279).

${ }^{10}$ Ver Juan Flores, “The Latino Imaginary...”, especialmente sus aproximaciones demográfica, analítica e imaginaria al tópico de la unidad y diversidad de los latinounidenses (185-190). Desde luego que una consideración cabal de las negociaciones culturales de la panlatinidad debe, por fuerza, incluir el importante hecho de las constantes migraciones y las “migraciones circulares” (el retorno) de tantos latinos en los EE.UU.

${ }^{11}$ Entendiendo "panlatinidad" como el imaginario posnacional de los grupos étnicos latinounidenses descrito por Flores (“The Latino Imaginary”) y Madrid (“Juntos y revueltos”).

${ }^{12}$ Término favorecido por Marc Zimmerman, quien lo analoga a "panlatino", en el sentido de una formación de grupo que emerge de la interacción o confluencia histórica de dos o más etnias latinas relacionadas culturalmente. Por otra parte, Juan Flores utiliza "translatino"en referencia al conglomerado latinounidense visto como una comunidad transnacional, caracterizada por un reflujo continuo de individuos entre los Estados Unidos y su país de origen, un sentido dual de identidad y un apego ambivalente a dos naciones, además de una extensa red de parentesco y relaciones amistosas a través de fronteras internacionales (para una ampliación de este concepto, ver Duany).
} 
en la macrocultura norteamericana, nos resulta unificadora. Al mismo tiempo, el favorecer la panlatinidad nos aleja de una exclusiva identificación con nuestros respectivos países de origen y sus culturas y literaturas nacionales (que siguen floreciendo, como es natural) y -para bien o para mal- nos reconfigura como "juntos y revueltos", inmersos en la sociedad consumidora y supuestamente pluralista de los EE.UU. ${ }^{13}$

En textos por otra parte tan étnicamente idiosincrásicos, y tan disímiles entre sí, como las narraciones de En la Ocho y la Doce de Roberto Fernández, la novela ;Yo! de Julia Alvarez, los ensayos de Pat Mora en Nepantla, la narrativa de Esmeralda Santiago-Almost A Woman-y la ficción de Elías Miguel Muñoz en Brand New Memory, se empiezan ya a vislumbrar vestigios de una conciencia panlatina que va dejando de ser lo que fue estrechamente en los entornos chicanos, puertorriqueños, cubanos, dominicanos, para constituirse en comunitaria identificación, no sólo ya reconocible por la mayoría anglosajona, sino innegable para los mismos miembros del conglomerado latinounidense.

Resulta obvio que los más visibles portaestandartes de la cultura latinounidense han sido los intérpretes de la música popular, la cual en su versión latina ha venido tomando por asalto los escenarios norteamericanos desde hace décadas, y hoy en día disfruta el éxito global que viene de su aceptación por los públicos anglohablantes y los mercados que de éstos se derivan (piénsese en el impacto de figuras como Tito Puente, Gloria Estefan, Willie Colón, Selena, Marc Anthony, Jennifer López). Pero asimismo, los últimos quince años han confirmado indiscutiblemente la fuerte presencia de escritores latinos en las casas editoriales mayores del país. Nombres como Julia Alvarez, Oscar Hijuelos, Ana Castillo y Sandra Cisneros -por sólo mencionar algunos de los más vendidos y elogiadosaparecen en listas, librerías y hogares donde se cultiva su lectura desde hace años. En los Estados Unidos, el término "escritores latinos" tiene ya su nicho aparte, separado de los afamados autores latinoamericanos más leídos en el país: Allende, García Márquez, Valenzuela, Fuentes, Ferré. ${ }^{14}$

¿Cómo se perfila esa panlatinidad incipiente en los textos mencionados? ¿En qué rasgos comienza a dibujarse al menos un vestigio de esa conciencia de ser parte de un grupo unido por su origen a lo latinoamericano, que se siente "otro" en su idiosincrasia marginal de minoría estadounidense, distinguida tanto por su carácter hispánico/mestizo como por lo que la acerca a la mayoría anglosajona? En un artículo publicado en el número especial de Discourse dedicado a los discursos latinos en la academia norteamericana, Marcus Embry discute las “sombras de latinidad” presentes en la literatura norteamericana del mainstream (hilos de tradiciones como la leyenda mexicana/chicana de La Llorona). Diremos entonces que estas páginas nuestras ofrecen una lectura incipiente de las

\footnotetext{
${ }^{13}$ Ver Arturo Madrid. Le agradezco al Dr. Madrid, Murchison Distinguished Professor of the Humanities en Trinity University, la gentil invitación que me extendiera a compartir con los alumnos en su curso "The U.S. Latino Experience”, y los textos suyos que generosamente me ha facilitado. ${ }^{14}$ Aunque a esta última, no obstante, a veces se la agrupa junto a las latinaunidenses, sobre todo después de publicar originalmente en inglés The House on the Lagoon y Eccentric Neighborhoods (ver Kevane y Heredia, Latina Self-Portraits, que incluye entrevistas con Julia Alvarez, Denise Chávez, Sandra Cisneros, Rosario Ferré, Cristina García, Nicolasa Mohr, Cherríe Moraga, Judith Ortiz Cofer, Esmeralda Santiago y Helena María Viramontes).
} 
"sombras de panlatinidad" que asoman en los textos de autores chicanos, cubanoamericanos, dominicanoamericanos, y neorriqueños. ${ }^{15}$

En el texto de Miguel Elías Muñoz Brand New Memory, se dibuja el personaje central de Gina Domingo como una adolescente en búsqueda de su propia identidad, que cree encontrar definitivamente en las tiendas y cinematógrafos de California del Sur .... hasta que conoce a su abuela cubana. La "Princesa” se da cuenta al final de que su sueño dorado de ser actriz, sus ilusiones maquilladas de celuloide, no encajan en la realidad familiar. Pero esa es la segunda parte de la novela. Mientras tanto la teenager Gina -nacida en el mundo suburbano de Los Angeles- se nos presenta en una escena visual. Fotos desvaídas, circa 1966: la familia Domingo, todavía como exiliados, sentados en el living room de su primer apartamento en California. Después, el nacimiento de una verdadera CAP (Cuban American Princess), y lo que ésta necesita, según el narrador, para propiamente soportar la angustia existencial de la adolescencia: "movies, pizza, malls, a pretty bedroom, a computer, cute guys, dances” [películas, pizza, centros comerciales, una habitación bonita, una computadora, muchachos guapos, bailes"] (5) Esta cubanoamericanita vive dentro del mundo de la Southern California pop culture; sin embargo, sus padres todavía lidian con el desarraigo, y la vida de toda la familia cambia cuando la abuela, Estela, viene de Cuba a visitarlos. La abuela, a través de su cocina y de sus cuentos de la Isla -que para la imaginación de Gina son como sus amadas películas de Hollywood- comienza a abrir una oportunidad nueva para la nieta: la recreación de un pasado cubano al cual puede aspirar libremente y construir para sí “a brand new memory”. Las historias y cartas de Estela han (re)creado la herencia cultural de Gina, y cuando ésta visita después Cuba (re)conoce que entre las dos han fabricado una memoria nueva de su propio ser, recuerdos nuevecitos que son suyos. No obstante, la abuela no encaja en el mundo de la nieta, en la urbanización de Pinos Verdes, rodeada de muros y con sistemas electrónicos de seguridad. Gina piensa que si Estela caminara sola por las calles de su barrio residencial, la siguiente escena se desarrollaría:

A solitary town where the police would stop a Cuban woman walking by herself. Where are you from, lady? Show us your ID, a driver's license, a passport, anything. Are you somebody's maid? Who do you work for? How did you get past the guards? You don't belong in Pinos Verdes! (148) ${ }^{16}$

Solamente la apariencia de la mujer madura la delata como "diferente" (latina en su fenotipo o vestuario, quizás ilegalmente en el país), en ese mundo extraño de los suburbios

\footnotetext{
${ }^{15} \mathrm{El}$ último término se refiere en español a lo que en inglés se denomina "neorrican”, definido por Alberto Sandoval como un movimiento literario caracterizado por "un bilingüismo arraigado, una denuncia a la pobreza, a la discriminación y al racismo del sistema anglo-americano, y un llamado al orgullo étnico y cultural boricua”: ver "La identidad especular del allá y del acá: nuestra imagen puertorriqueña en cuestión” 28, citado en Efraín Barradas, “Mira, mira, mira: Juan Sánchez, pintor neorrican", en su Partes de un todo..., 203-204.

16 "Un pueblo solitario donde la policía detendría a una mujer cubana que caminara sola: ¿De dónde es Ud., señora? Muéstrenos su identificación, su pasaporte, cualquier cosa. ¿Es Ud.la sirvienta de alguien? ¿Para quién trabaja Ud.?¿ Cómo pudo pasar sin que la detuvieran los guardias? ¡Ud. no pertenece a Pinos Verdes!”
} 
acomodados de Los Angeles, los guardias - piensa la nieta- la interrogarían como si fuese una sirvienta indocumentada. La narración del episodio termina con las siguientes conclusiones:

This world and Abuela were incompatible, each belonged in separate, irreconcilable dimensions. She didn't fit here and neither did Cuba. She was alone, stranded on Gina's strange planet (148). ${ }^{17}$

En otras palabras, para el mundo de clase media de una adolescente "integrada" al estilo de vida mayoritario, el país de origen no encaja, Cuba es una ausencia en lugar de una presencia, como la abuela que partirá cuando se cumpla el plazo de su visita. El mundo de una cubanoamericana joven, nacida en California, es un planeta extraño para los cubanos, aun para su propia familia que ha triunfado económicamente en el destierro. Sin embargo, al comienzo de la trama, la Princesa sonreía, bailaba en su mundo color de rosa, necesitaba "designer clothes and CDs, cable, frozen yogurt" [ropas de alta costura y discos compactos, televisión por cable, yogurt congelado](6).

Evidentemente, el mundo de Gina Domingo trata de fundir y de integrar las experiencias de clase media de los adolescentes "mainstream", no minoritarios, anglosajones. Su latinidad aflora sólo cuando la abuela aparece, un ser extraño aunque amoroso, que sirve de contraste a la fingida condición “normal” de la adolescente. Aunque viva más allá de ciertas barreras socioeconómicas, aunque pueda "pasar" en apariencia, aunque hable inglés perfectamente, la muchacha se siente "otra" con respecto a sus orígenes y al medio que la rodea. Suya es la eterna condición de los étnicos: la hibridez que causa el no ser aceptado completamente ni en un mundo ni en otro. Condición tampoco exclusiva de los inmigrantes políticos, ni suramericanos ni caribeños: muchos resultan diferentes, sospechosos ante las autoridades por su color, o su lengua o su vestimenta sospechosos, de no pertenecer al lugar donde se encuentran. Los descendientes de cubanos (o peruanos, o costarricenses, o venezolanos), aunque ciudadanos de nacimiento y asimilados en sus costumbres, su idioma adolescente, sus usos consumidores, adquieren en un momento u otro de su desarrollo mental y emocional las sensaciones de la “otredad", herencia extraña de los que viven en los márgenes culturales aunque parezcan asimilados: la familia de origen, tan crucial para los latinos, se convierte así en índice de diferencia y marginalidad. En ese sentido, el personaje Gina parece atravesar por un proceso de transculturación o "tropicalización”, ${ }^{18}$ "recubanizándose” para el mundo latinounidense en el que reside permanentemente.

En el caso de cubanos inmigrados a los EE.UU., los personajes de Brand New Memory, es significativo que la figura de la abuela sea "latinizada" en la imaginación protagónica como indocumentada, racializada y clasificada como indeseable (aunque las definiciones de latino/a postuladas por los medios masivos de comunicación sean

\footnotetext{
17 "Este mundo y la Abuela eran incompatibles, cada uno pertenecía a dimensiones irreconciliables y separadas. Ella no cabía aquí ni en Cuba tampoco. Estaba sola, varada en el extraño planeta de Gina.”

${ }^{18}$ Para una explicación del concepto de “tropicalización”, ver nota 37.
} 
diferentes y aun opuestas, en su “tropicalización” triunfante de las imágenes de individuos latinos). Por décadas, los medios masivos se han hecho eco de extendidos juicios sobre la mentalidad exílica y ultraconservadora de los cubanoamericanos, que no reconoce pertenecer a minorías étnicas estadounidenses por razones políticas y clasistas, haciendo extensivo a generaciones jóvenes patrones ideológicos y socioeconómicos que corresponden principalmente a la población cubana arraigada en Florida, y no a otros cubanoamericanos que a menudo se autoconsideran tan minoría étnica como los chicanos o los puertorriqueños -a pesar del persistente mito del “Cuban success story” y el privilegiado lugar que, según muchos, parecen ocupar los latinos de origen cubano en la sociedad norteamericana (Rivero, Discurso Literario 96). La abuela Estela, en un barrio acomodado de Los Angeles, no "pasaría”: en la concepción adolescente de Gina, el estereotipo se cumple y realiza en esa su familiar latinidad -según ella- aparente.

He aquí que la incipiente conciencia de ser diferente, por una difusa "condición latina” que se demuestra en lo externo de la persona, surge a nivel interno en el personaje central de Brand New Memory, novela de cubanoamericanos radicados en California, estado donde la población latina -predominantemente chicana y centroamericana- no pertenece, ciertamente, al imaginario social que el Establishment propaga, a pesar de sus números crecientes y sus perfiles demográficos. Eso sobresale en la narración de Muñoz, sobre todo en las figuras de los guardianes del orden, pero más que nada en la imaginación de Gina Domingo, donde una vaga y estereotipada concepción de "lo latino" se funde y confunde con lo cubano, en momentos sobrepasando y aun ocultando la particularidad etnosocial de ese grupo determinado. ${ }^{19}$

Por otra parte, la declaración afirmativa de presencia, la aceptación de una comunidad en general latina se menciona ya en libros anteriores, en obras tan culturalmente idiosincráticas de lo mexicano y lo méxicoamericano como la colección de ensayos de la poeta Pat Mora, Nepantla: Essays from the Land in the Middle. ${ }^{20}$ En particular, el ensayo "Endangered Species” (“Especie en peligro de extinción”) se refiere a la preservación de la herencia cultural latina, a la real invisibilidad de los latinos en todas las imágenes que la sociedad ofrece de sí misma, al valor de la diferencia y lo que ésta significa para valorar "lo latino". Ya en 1993, la conocida poeta chicana se identifica en el contexto nacional como parte de la panlatinidad. A la par que reconoce el "feroz orgullo" de la herencia mexicana de sus abuelos (18), reitera su pertenencia a la comunidad nacional latina, o panlatina, en los siguientes términos:

We, Latinas and Latinos, need to become more vocal about our group heritage and more critical of the values of consumerism, violence, and social stratification that arrive silently in our mailboxes and appear almost everywhere we look. Sorely missed writer and university president Tomás Rivera told us that Chicano academics and the Chicano

\footnotetext{
${ }^{19}$ Puede ser que la conciencia latina en Gina sea resultado de estar “desplazada” (fuera del enclave cubano floridano), y también sea producto de su identidad generacional adolescente.

${ }^{20}$ El término nahuatl nepantla significa literalmente "la tierra de en medio", y se refiere simbólicamente a la experiencia cultural de vivir entre dos espacios, sin pertenecer por completo a ninguno de los dos (concepto ampliado y diseminado por Gloria Anzaldúa en su renombrado libro Borderlands.La Frontera: The New Mestiza).
} 
community need to work together.... Who is ensuring that the history of Latinas and Latinos in this country is being accurately and compellingly taught and that our present artists, whether in traditional or emerging art forms, are receiving a just portion of both the public and private support available? Who determines our aesthetic standards? $(31)^{21}$

La preocupación por el futuro de la cultura y la historia de los latinos en los Estados Unidos revela una conciencia de la importancia de una unión interétnica que asegure nuestras propias visiones, definiciones y criterios. Resulta particularmente interesante ver cómo, en medio del pasaje en que se declara la latinidad como un conglomerado nacional, el ejemplo utilizado por Mora es específicamente chicano, en la figura de unos de los autores literarios y líderes educacionales más reconocidos en la comunidad intelectual méxicoamericana. De ahí, se vuelve a insistir en la necesidad de la iniciativa propia en el proceso constructor de una identidad, y se retorna a la autoinclusión en el imaginario nacional panlatino. La última pregunta revela aún más la interiorización de una conciencia de grupo, al dar por sentado que existen patrones y criterios estéticos relativos a la comunidad latinounidense, que la ensayista toma como punto de referencia para la revelación de sus inquietudes con respecto al futuro de "nuestra” producción cultural.

En otros ensayos de Nepantla también se observa la doble referencialidad, esa pertenencia a lo chicano dentro de lo latino, aun en el contexto del suroeste norteamericano. En "Desert Women" [Mujeres del desierto], aparece una defensa de aquellas mujeres sujetas a la duplicada marginalidad de lo latino y lo femenino, y en el caso de la voz autobiográfica del texto se reconoce la mexicanidad inmersa en la latinidad. Por ejemplo, un pasaje que cita la orgullosa tradición de las abuelitas y sus habilidades caseras, poniendo como ilustración a Sor Juana y sus guisos, y valorando lo específicamente positivo de la cultura mexicana con reflexiones durante un viaje a Oaxaca, va seguido inmediatamente de la siguiente afirmación:

Latinas are labeled a double minority. The words are depressing. They don't quite sound like "twice-blessed". Little wonder that most Latinas, whether in the Southwest or elsewhere in this country, don't dwell on this uncomfortable term. $(56)^{22}$

La referencia a las latinas del suroeste es definitivamente a las méxicoamericanas, entre las cuales se incluye Mora: "Many Mexican American women from the Southwest

\footnotetext{
21 "Nosotros, las latinas y los latinos, tenemos que proclamar en voz alta nuestra herencia de grupo, y ser más críticos de los valores del consumismo, la violencia y la estratificación social que llegan silenciosamente a nuestros buzones y aparecen en casi todos los lugares donde posamos la mirada. Tomás Rivera, escritor y rector universitario a quien extrañamos mucho, nos decía que los académicos chicanos y la comunidad chicana tenían que trabajar juntos...... ¿Quién asegura que la historia de latinas y latinos en este país se enseña con exactitud y convicción y que nuestros artistas actuales, sean en sus formas tradicionales o emergentes, reciben una porción justa de los fondos públicos o privados que estén disponibles? ¿Quién determina nuestros patrones estéticos?”

22 "A las latinas se les pone la etiqueta de doble minoría. Las palabras son deprimentes. No suenan del todo como 'doblemente benditas'. No en balde la mayoría de las latinas, sea en el suroeste o en otro lugar de este país, no se detienen en este término incómodo.”
} 
are desert women. We “know about survival /...Like cactus / we’ve learned to hoard.”23 La discriminación o menosprecio de las mujeres en tanto que latinas poco hace por ellas, y menos que nada "bendecirlas": por eso en ninguna parte de los EE.UU. la expresión de doble minoría les resulta cómoda a las mujeres de ascendencia hispana. No obstante, la argumentación del ensayo sigue ampliando el horizonte etnocultural de la autora, quien páginas más adelante pregunta: "How do we create a space for ourselves to be ourselves, our multiple Latina, Hispana, Mexicana, Chicana selves?” (67) ${ }^{24}$ En la progresión identificadora de identidades, el término que corresponde a la comunidad posnacional, a la panlatinidad, forma el extremo generalizado e incluyente de la ecuación: de ser general "latino", tal como nos ve la mayoría y como nos consideramos todos los que cabemos en esta denominación, a ser hispanos (tanto el calificativo de los anglos para los latinos como la autodenominación de los nuevomexicanos descendientes de españoles) o mexicanos o chicanos -la especificidad del subgrupo latino en el suroeste. Como es evidente, la conciencia de lo panlatino hace acto de presencia en estas páginas de Pat Mora de manera explícita, y aun cuando la escritora se asocie definitivamente a su grupo étnico particular, sus escritos patentizan una manera panlatina de contemplar el universo cultural de los latinounidenses.

En la celebrada obra de ficción de Julia Alvarez, su novela ; Yo! -narrativa sobre una escritora en formación- pone en boca de diferentes personajes y familiares de la protagonista, Yolanda García, un latente discurso latinounidense. A pesar del explícito carácter dominicano inmigrado de los que pueblan el universo neoyorquino de la obra, la protagonista se describe desde varias perspectivas como una latina que habla un inglés perfecto y encuentra su felicidad en la convivencia con su escritura y, al final, con un hombre angloamericano. La composición del personaje central se da como un collage narrativo de distintos puntos de vista, entre los cuales sobresalen, para nuestro propósito, el de la madre y la casera de Yo. La primera, Laura/Mami, lucha con el idioma -el más difícil factor en su adaptación al nuevo ambiente. Con el característico humor que distingue a Alvarez, la voz de Mami abre el capítulo sobre los recuerdos de la isla que han dejado atrás, con un recuento de las vicisitudes neoyorquinas comunes a los inmigrantes caribeños:

To tell you the truth, the hardest thing coming to this country wasn't the winter everyone warned me about -it was the language. If you had to choose the most tongue-twisting way of saying you love somebody or how much a pound for the ground round, then say it in English. For the longest time I thought Americans must be smarter than us Latins because how else could they speak such a difficult language. After a while, it struck me

\footnotetext{
23 "Muchas mujeres méxicoamericanas del suroeste son mujeres del desierto. Sabemos "de la sobrevivencia... como los cactus, hemos aprendido a acaparar" (en estas líneas, la autora cita uno de sus poemas, de igual título que el ensayo, "Desert Women”, publicado en su libro Borders [Fronteras], 80).

24 “¿Cómo podemos crear un espacio nuestro para ser nosotras mismas, nuestras múltiples identidades como latinas, hispanas, mexicanas, chicanas?”
} 
the other way. Given the choice of languages, only a fool would choose to speak English on purpose. $(21)^{25}$

El monólogo interior de Mami revela la dificultad de adaptación del inmigrante latino, además de identificar el grupo al que se asocia la caribeña recién llegada: "us Latins". Sin embargo, al final del capítulo, las hijas de Laura ya están parloteando en inglés como si fuera su lengua materna: "jabbering away in English like there were born to it" (35). Tal es así, que las primas que se han quedado en la República Dominicana se refieren a las hermanas García como gringas locas -“those crazy gringa cousins...” (37). En la proliferación de adjetivos referentes a los personajes, se encarna la traslación de subjetividades con respecto a la lengua y a la etnia de estos latinounidenses en ciernes. De Santo Domingo a Nueva York, en una generación se transforman los horizontes del paradigma y los extranjeros devienen ciudadanos, mientras los más jóvenes efectúan entre ellos el paso que los llevará -según su propia apreciación-a latinounidenses, ciertamente en comparación con los que han quedado atrás en la tierra de origen.

No obstante, Yo -con su inglés intachable, su piel canela y su larga trenza, sus ojos agresivos, sus aspiraciones a puestos académicos-flota en la nebulosa zona del ser-no ser, por su aspecto y modos de ver diferentes. Su centro espiritual, según ella, es el idioma que maneja con facilidad elegante, por lo cual se ha convertido en su patria adoptiva, como escritora desarraigada al fin. La casera de quien alquila un apartamento la escucha y piensa:

...she's not originally from this country but came when she was a kid and now she has this job over at the college. All the time I'm wondering if she's giving me some story because she's talking English better than me. So I say, "You sure picked up English", and she looks at me a moment and says, "Language is my only homeland. (153) ${ }^{26}$

Nótese que en la caracterización que la casera hace de la mujer, diferente a sí misma, que ve frente a sus ojos, prima el estereotipo globalizador del "latino-como-extranjero", reacción propia de la conducta anglosajona al enfrentarse por primera vez a una persona de piel más oscura que la suya, de cabello diferente, de apellido García. Este fenómeno ha sido estudiado inclusive desde una perspectiva legal, ya que frecuentemente los ciudadanos

\footnotetext{
25 “A decir la verdad, lo más duro al venir a este país no fue el invierno contra el cual todo el mundo me había prevenido -fue el idioma. Si tienes que escoger la manera más enredada de decirle a alguien que lo quieres o cuánto por una libra de picadillo, entonces dilo en inglés. Por mucho tiempo pensé que los americanos debían ser más inteligentes que nosotros los latinos -porque si no cómo podían hablar una lengua tan difícil. Después de un tiempo, me pareció lo contrario. Si a uno le dieran a elegir el idioma, sólo un bobo escogería hablar inglés a propósito”.

26 “...ella no es originalmente de este país pero vino cuando era niña y ahora tiene un trabajo en el college. Mientras tanto me pregunto si me está haciendo un cuento porque habla inglés mejor que yo. Y le digo, 'Pues sí que agarraste el inglés”, y ella me mira un momento y dice, 'El idioma es mi única patria”. Otros escritores latinounidenses, especialmente poetas, han cultivado este concepto; confrontados por la invisibilidad, el escribir para ellos es un acto de salvación, las palabras devienen el único territorio posible. Por ejemplo, la chicana Lorna Dee Cervantes: "I go to my land, my tower of words and bolt the door..." ("voy a mi tierra, mi torre de palabras y le paso cerrojo a la puerta..."; Rivero, “Hispanic Literature...”, 189).
} 
latinos de los EE.UU. son vistos como extranjeros indeseables, como intrusos. ${ }^{27}$ En las páginas de Julia Alvarez, la caracterización latina de la protagonista a través de la mirada de los anglos conlleva esa conciencia de la diferencia vivida en carne propia que los latinos, sean inmigrantes o naturales del país, comparten comunalmente en el ámbito nacional.

En la narrativa de Esmeralda Santiago hay ciertos paralelos con los asuntos de las narraciones de Julia Alvarez: historias de inmigrantes caribeñas a Nueva York que deben sumergirse en los barrios hispanos de la Babel de Hierro y adoptar una identidad que les permita sobrevivir. En las dos autoras hay un decidido compromiso con sus raíces y una perspectiva abierta al futuro, aparte de un ángulo de enfoque decididamente femenino. Hay, desde luego, diferencias de etnia insular y de clase entre los dos asuntos, especialmente mediante el carácter claramente autobiográfico que Santiago prefiere dar a sus textos. Por otra parte, la crítica coincide en otorgar a Alvarez el galardón de una más creadora y pulida perspectiva, tanto autorial como ficticia. Dicho esto, existe asimismo la común experiencia de la figura materna que rige los destinos de sus hijos con mano autoritaria, y no con miedo a que los nuevos y extraños ambientes erosionen la cultura familiar (veánse, en este respecto, los personajes de las madres que crea Alvarez en How the García Girls Lost Their Accents, más recientemente en In the Name of Salomé, y los que describe Santiago en When I Was Puerto Rican).

Ciertamente, las experiencias de los personajes autobiográficos de Santiago reciben atención del público lector angloamericano que se abre a las posibilidades de conocer la pluralidad de sus entornos. Con relación al proceso de transculturación común a los inmigrantes que se enfrentan a la cultura mayoritaria, surge asimismo la comparación con las primas “agringadas”:

Mami said they [her cousins, Alma and Corazon] were "Americanized”. The way she pronounced the word Americanized, it sounded like a terrible thing, to be avoided at all costs, another algo to be added to the list of 'somethings' outside our door" (12). ${ }^{28}$

Resalta en esta cita la resistencia a la asimilación como un peligro inminente que acecha a los latinos que desean retener su identidad etnocultural, aun en medio del proceso necesario de adaptación a la sociedad (al menos externamente) adoptada.

\footnotetext{
${ }^{27}$ Ver Kevin Johnson, “Citizens as Foreigners”, en Delgado y Sefonic (ed.) The Latino/a Condition, 198-201. Este importante aporte al diálogo nacional responde a la tesis xenofóbica de Peter Brimelow en su libro Alien Nation (1995), quien acusa a los líderes latinos de los EE.UU. de crear una identidad hispánica "artificial” con propósitos ilegítimos. Esencialmente, la tesis de Brigelow afirma que como todos los latinounidenses son extraños a las raíces anglosajonas de la nación, se deben tomar medidas drásticas para impedir que ningún otro latino inmigre. Según su criterio, todos los latinos forman un conglomerado semejante, agrupados por su disparidad con el imaginario anglo, y unidos en su indeseable diferencia (Johnson 198-99).

${ }^{28}$ Mami decía que [las primas suyas, Alma y Corazón] estaban "americanizadas”. La forma en que pronunciaba la palabra americanizada, sonaba como algo terrible, que se debía evitar a toda costa, otra cosa que añadir a la lista de 'algos” fuera de nuestra puerta (12).
} 
Por otra parte, Esmeralda aprende que los suburbios horizontales de los “americanos blancos”, los otros Estados Unidos, son un universo donde no viven los latinos que ella conoce, y ciertamente no ve ninguno en las páginas de su lectura favorita, las historietas de Archie y Verónica (26-27). Las muchachas como ella son sólo el blanco de los asedios de hombres anglos que las quieren como "hot tamale” latinas, mujeres sexualizadas (247). En el vergonzante episodio con el millonario Avery Lee, éste le ofrece un apartamento en Texas y cualquier otra cosa que ella desee: pero no puede casarse con ella porque tiene ambiciones políticas, y una "Spanish wife" le impediría llevarlas a cabo. Por último, le dice el tejano a Esmeralda,

"My daddy has had a Mexican for twenty years, he confided. "He loves her more than life”, he added. “A Mexican what?” I bit out. "I’m being honest with you”, Avery Lee sulked. My eyes itched, and I was having trouble breathing, my hands shook with the desire to strangle him. $(248)^{29}$

Ante los ojos del hombre anglo, Esmeralda es “Spanish” (lo mismo da puertorriqueña de Nueva York que mexicana de Tejas, al fin y al cabo), catalogada en el grupo de mujeres no aptas para un matrimonio de conveniencia económica o política, ni por supuesto de amor. En otras palabras, al ser igual una latina que la otra, la noción de panlatinidad se manifiesta irónicamente en estas páginas por medio de una noción sexualizada y racializada que engloba por igual a todas las etnias culturales latinas: las hembras del grupo sirven para la satisfacción del deseo, no para ocupar un lugar legítimo en la sociedad. En el sentido genérico y sexual, se cumple asimismo para las mujeres lo que para los hombres latinos: ser ciudadanos de segunda clase.

La lealtad a la cultura de origen, a lo etnonacional, no es uno de los rasgos con que se describe a sí misma la Esmeralda de Almost A Woman. Uno de los puntos más interesantes de la narración surge cuando Jaime, nuyorriqueño de nacimiento y actor en una obra teatral de asunto hindú al igual que la protagonista, pronuncia un fuerte alegato en pro de la obligación que ambos tienen de defender el arte, el teatro, la cultura boricuas.

"You don’t get it”, Jaime argued, "if we lose Puerto Ricans to other cultures, we lose Puerto Rican culture”. (My devotion to Indian dance, I argued, wasn't part of a conspiracy to promote their civilization over Puerto Rico's). "What do you think happens to us here?” I contended. "Do you think we're as Puerto Rican in the U.S. as on the island?" "More”, he argued. "We have to work at it here". (286) $)^{30}$

\footnotetext{
29 “Mi papá ha tenido una mexicana por veinte años”, me confesó. "La quiere más que a su vida”, añadió. “¿Una mexicana qué?” respondí mordaz. “Soy franco contigo”, Avery Lee dijo enfurruñado. Los ojos me ardían, me costaba trabajo respirar, las manos me temblaban con los deseos de estrangularlo.

30 "No te das cuenta", afirmaba Jaime, "si perdemos los puertorriqueños a otras culturas, perdemos la cultura puertorriqueña”. (Mi dedicación a la danza hindú, decía yo, no era parte de una conspiración para promover su civilización por sobre la de Puerto Rico). “¿Qué crees tú que nos pasa a nosotros aquí?”, insistí yo. “¿Tú crees que aquí en los Estados Unidos somos tan puertorriqueños como en la isla?” "Más todavía”, argüía él. "Aquí tenemos que hacer el esfuerzo por serlo”.
} 
Por supuesto que el contexto de la pérdida de la cultura boricua es el pluralismo neoyorquino, pero resalta en el comentario el hecho de que para mantener la puertorriqueñidad, la latinidad en los EE.UU. hay que hacer un esfuerzo laborioso que no se necesita en los países donde la cultura mayoritaria nacional es idéntica a la nuestra: en otras palabras, donde se es mayoría, lo cultural propio se da por sentado. En ese mismo sentido, se ha cuestionado también el por qué Santiago considera que ya no es puertorriqueña (dado el título de su primer libro, “Cuando era puertorriqueña”) (Barradas 201-02). Lo cierto es que la autora explica lúcidamente su proceso transformativo, y el título When I Was Puerto Rican, en una nota cibernética escrita para los lectores de sus libros. En ella aclara que cuando regresó a Puerto Rico después de vivir en Nueva York siete años, le dijeron en la isla que ya ella no era puertorriqueña porque su español había caído en desuso, y su personalidad era demasiado agresiva para una mujer de Puerto Rico.

I felt as Puerto Rican as when I left the island, but to those who had never left, I was contaminated by Americanisms, and therefore, had become less than Puerto Rican. Yet, in the United States, my darkness, my accented speech, my frequent lapses into the confused silence between English and Spanish identified me as foreign, non-American. In writing the book I wanted to get back to that feeling of Puertoricanness I had before I came here. Its title reflects who I was then, and asks, who am I today?”31

Aquí nos topamos de nuevo con la noción de que sentirse latina/o equivale a sentirse extranjera/o, no norteamericana/o. En el imaginario nacional creado por los anglosajones a partir de su fundación de las trece colonias en el este, los españoles establecidos y aun nacidos en el suroeste y el oeste del gran territorio pre-Estados Unidos en los siglos XVI, XVII y XVIII -como nuevohispanos o californios- no “existían”, así como desde luego no “existían” los indígenas naturales del vasto país, ni “existieron” los tejanos que ocupaban extensas tierras después de la independencia de México en 1821. Los mexicanos legítimamente establecidos en sus territorios de origen, al norte del virreinato de la Nueva España, pasaron a ser extranjeros en su propia tierra, y la fundación misionera que después sería la gran ciudad de California, La Puebla de Nuestra Señora de Los Angeles, se convirtió simplemente en "L.A.”. El legado histórico hispánico queda excluido de las construcciones sociales de los EE.UU. como nación, y silenciado con el mito de Jamestown, la supuesta primera colonia europea fundada en la América del Norte en 1608 -excepto que los españoles llegaron a la Florida y al suroeste en el siglo anterior. La noción del latinounidense como extranjero es, entonces, eminentemente antihistórica, y la creación de la conciencia panlatina -tal como se define en estas páginas- es una de las estrategias correctivas que puede alimentar una clara visión de lo que sean en realidad los Estados Unidos de América.

31 “Yo me sentía tan puertorriqueña”, dice, “como cuando dejé la isla, pero para los que no se fueron, yo estaba contaminada de americanismos, por tanto, me había convertido en menos puertorriqueña. Y sin embargo, en los Estados Unidos, mi piel oscura, mi acento al hablar, mis lapsos frecuentes en el confuso silencio entre inglés y español me identificaban como extranjera, como no-americana. Al escribir el libro yo quería volver al sentimiento de puertorriqueñidad que tenía antes de venir. Su título refleja lo que yo era entonces, y pregunta, ¿quién soy hoy?” Esmeralda Santiago, en “A Note to the Reader”. 
Por lo que respecta a Esmeralda Santiago, sus textos revelan una conciencia de la “extranjería” del latino (sea puertorriqueño de la isla o de Nueva York), de la diferencia capital entre esos individuos de piel oscura e inglés acentuado y los "verdaderos" estadounidenses, los que no son de color ni hablan con acento. Si bien la autora no considera patentemente la latinidad como una estrategia cultural (al menos en las páginas de sus libros), no cabe duda de que su aspiración a integrarse en el mainstream la aleja de un horizonte étnico reducido. Probablemente, ese es uno de los factores que han convertido sus narraciones autobiográficas en éxitos de librería.

La editorial Houghton Mifflin anunció En la Ocho y la Doce de Roberto Fernández, el único texto escrito en español que consideramos en estas páginas, en la forma siguiente:

Cultural Value: while reflecting the experiences of Cuban immigrants, these stories also sensitively portray the experiences of thousands of U.S. Latinos whose voices are seldom heard. ${ }^{32}$

En este caso, aun antes de leer las narraciones, surge una "sombra de panlatinidad" mediante la estrategia de mercadeo utilizada para vender el libro, así como la apreciación generalizada de una comunidad nacional cuyas vidas y destinos se hace preciso conocer. ${ }^{33}$

Quizás uno de los episodios de asunto más reconocible para un público latino general sea "El Show de Titina" (105-28), donde la protagonista -estrella televisiva con su espectáculo diario en que entrevista a diferentes latinos, generalmente inmigrantes establecidos en la Florida- hace propaganda comercial para la compañía de teléfonos Titiphone, con servicios extensivos a toda la América Latina. ${ }^{34}$ Pero la narración que probablemente contenga más alusiones panlatinas es “Circular navideña” (175-77), carta colectiva en que una familia de latinos de clase media en Boston felicita a sus familiares y amistades con ocasión de las fiestas pascuales. El texto, si bien en español, contiene toda una serie de referencias interculturales a la familia firmante: el matrimonio (Miguel) “Mike” y (Jimena) “Jean” Pardo, y sus hijos Erin y Kyle (nombres típicos de jóvenes anglos de clase media alta, o “yuppies”). Estos últimos, a la manera de Gina Domingo en

\footnotetext{
32 "Mientras refleja las experiencias de los inmigrantes cubanos, estos cuentos también retratan con sensibilidad las experiencias de miles de latinounidenses cuyas voces no se oyen con frecuencia." El comentario aparece entre los apuntes que, con respecto a En la Ocho y la Doce, forman parte de una carta enviada por la editorial junto al libro de muestra; éste, claramente, es un texto destinado al público hispanoleyente, con seguridad escolar o universitario. El libro forma parte de las publicaciones en la serie "Nuestra visión: U.S. Latino Literature".

${ }^{33}$ Resulta interesante apuntar que algunos de los episodios que constituyen cuentos o capítulos individuales habían aparecido en inglés en la novela de Fernández Raining Backwards, como por ejemplo el “milagro” en la esquina de la Calle Ocho y la Avenida Doce en la Pequeña Habana, barrio cubano de Miami; el personaje de Mirta al recrear la playa cubana de Varadero en su bañera miamense, devorada por la nostalgia; las burlescas descripciones de las fiestas de quinceañeras y, desde luego, la figura misteriosa de San Guiven, acompañado por sus pavos.

${ }^{34}$ Por supuesto que las referencias no se explicitan en el cuento de Fernández, pero casi cualquier latinounidense reconocería la alusión al "Show de Cristina" en Univisión, y sus anuncios de la multinacional telefónica ATT (siglas que al pronunciarse en inglés, suenan como "ei ti ti”, y de ahí la doble carga humorística de "ti ti phone” y del nombre "Ti ti na”).
} 
la novela de Elías Miguel Muñoz Brand New Memory, viven inmersos en la cultura adolescente norteamericana del mainstream, con prácticas de “cheerleading” la chica, y de flautista en la banda escolar el muchacho, en avergonzada negación de su cultura de origen (el padre quería que Kyle tocara el bongó, pero su hijo le respondió que era un instrumento muy escandaloso, 175)..$^{35}$

Esta viñeta culmina páginas después con la reproducción de una tarjeta navideña original que la familia Pardo también envía a sus amigos: la adaptación al español de un conocido villancico angloamericano, "Los doce días de Navidad” ("una codorniz [sic] en un peral, dos tórtolas, tres gallinas francesas, siete cisnes nadadores, ocho doncellas ‘ordeñantes’, y así sucesivamente”, 186). En esta parodia anglificada de las tarjetas de Pascua tradicionales en la cultura latina - "para desearles una Feliz Navidad y un Milenio pleno de venturas"- se pone de realce la asimilación que los latinos de clase media sostienen, paradójicamente, para demostrar su orgullo étnico en las tradiciones. El uso del español en estos episodios facilita la ilusión de que se mantiene una etnoidentidad hispana, aun cubana, pero el gesto del envío masivo y la apropiación de fórmulas angloeuropeas (vista claramente en los íconos culturales del “Christmas carol”, objetos extraños al ambiente hispano-latino) desafían la obvia traducción y revelan la transculturación o tropicalización rampante que los usos comerciales y las estrategias de efectividad de la cultura hegemónica hacen obvia. Eso apunta, si bien oscuramente, hacia esas sombras de panlatinidad a que nos referimos anteriormente: es decir, a través de un tamiz de clase, los latinounidenses de ciertos recursos - no importa cuál sea su procedencia nacionaladoptan los modos comercializados de los anglos y se alejan de las costumbres regionales y populares de sus respectivas culturas de origen.

He aquí sin embargo que lo inverso, o sea la objetificación de productos culturales latinos, produce raros resultados. La cultura hegemónica se apropia de usos y objetos que reclama como parte del "gran conglomerado pluralista", y convence a los mismos originales usuarios latinos del "americanismo" de lo que fuera antes intrínseco a sus culturas. Lo que muchos observadores del fenómeno de la "latinomanía” en los Estados Unidos han caracterizado satíricamente (el perrito chihuaha de la cadena Taco Bell, las “fa-hee-tas” o “fajitas” de McDonald's) ${ }^{36}$ y señalado como reciclaje cultural, algunas entidades latinas de los EE.UU. lo atribuyen, no obstante, a una aplaudida penetración de lo latino en el mainstream, sin resaltar lo que estos usos tienen de expropiación “tropicalizada”. Claro que el contexto de esta transformación es el lucro comercial: véase, si no, el comentario aparecido en la página editorial del diario New York Times, firmado por el ex rector de la Pontificia Universidad Católica de Puerto Rico, Monseñor Lorenzo Albacete. Su columna, titulada “America’s Hispanic Future” [El futuro hispano de América], alude al impacto que le han hecho las vallas anunciadoras de una de las mayores

\footnotetext{
${ }^{35}$ Recuérdese que en un episodio de la serie que ha venido a (estereo)tipificar lo cubanoamericano en los EE.UU., I Love Lucy, protagonizada por la pareja de Lucille Ball y Desi Arnaz, el pequeño hijo de Ricky Ricardo ("Little Ricky”) toca el bongó en un episodio, imitando a su padre.

${ }^{36}$ Ver Aparicio, “On Sub-versive Signifiers: Tropicalizing Language in the United States”, 195. En la introducción al libro, las autoras se refieren al fenómeno de la "tropicalización hegemónica” (15), entre otras cosas, como "el conjunto de imágenes y atributos superimpuesto a los sujetos tanto latinoamericanos como latinounidenses por el sector dominante” (traducción nuestra).
} 
cadenas hispanas televisivas, en su aparición por toda la ciudad de Nueva York. Una, señala Albacete, le impresionó en particular: en ella, Univisión se autoproclamaba "as American as flan" (tan americana como el flan) (New York Times Online, 19 de junio de 2001). Si un objeto tan universalmente reconocible como producto de la gastronomía hispánica universal, el postre llamado flan, puede ser apropiado para el mainstream “americano" por una empresa dedicada a la (re)presentación de imágenes culturales masivas para los hispanohablantes de los EE.UU., caben dos interpretaciones. O el término “americano" pertenece a una visión del afamado multipluralismo norteamericano como dado por hecho, y el flan -por ser hispano/latino-pertenece entonces al imaginario social de la nación en general; o la apropiación de tal producto para la "cultura americana" (léase "dominante”) es marcadamente cínica o ignorante, y por ende en extremo ingenua la proposición que la red de televisión hispana plantea.

Sea como fuere, lo panlatino permea cada día más el entorno social de los Estados Unidos de América. Ya en textos literarios o culturales, ya en medios masivos de comunicación, las sombras de una latinidad imaginada como nacional, es decir, de una panlatinidad comprensiva y abarcadora de todas las etnias hispanolatinas que conviven y comparten la geopolítica y la geocultura de este extenso país, van aflorando cada día en mayor grado. Qué duda cabe que los exponentes celebérrimos de la cultura popular -los artistas, actores y músicos- han abierto una gran brecha para todos, pero los escritores y escritoras van ciertamente cerrando la marcha en este desfile de éxitos latinos con que parece abrirse la nueva centuria en los USA.

\section{BiBLIOGRAFÍA}

Abalos, David. Latinos in the United Sates. Notre Dame, IN: University of Notre Dame Press, 1986.

Alvarez, Julia. How the García Girls Lost Their Accents. New York: Plume/Penguin Books, 1991.

¡Yo!. New York: Plume/Penguin Books, 1997.

In The Name of Salomé. Chapel Hill, NC: Algonquin Books, 2000.

Anzaldúa, Gloria. Borderlands/La Frontera: The New Mestiza. San Francisco: Spinsters/ Aunt Lute, 1987.

Aparicio, Frances (ed.). Latino Voices. Brookfield, CT: Millbrook Press, 1994.

"On Sub-versive Signifiers: Tropicalizing Language in the United States". Tropicalizations: Transcultural Representations of Latinidad. Frances Aparicio y Susana Chávez-Silverman, eds. Hanover: University Press of New England, 1997. 194-212.

“Reading the 'Latino' in Latino Studies: Toward Re-imagining Our Academic Location”. Discourse 21/3 (Fall 1999): 3-18.

Augenbraum, Harold y Ilan Stavans (eds.). Growing Up Latino: Memoirs and Stories. New York: Houghton Mifflin, 1993.

Barradas, Efraín. “Esmeralda Santiago o cómo dejar de ser puertorriqueño” y “Mira, mira, mira: Juan Sánchez, pintor neorrican”. Partes de un todo: ensayos y notas sobre literatura puertorriqueña en los Estados Unidos. San Juan: Editorial de la Universidad de Puerto Rico, 1998. 199-02 y 203-21. 
Cortina, Rodolfo (ed.). Hispanic American Literature: An Anthology. Chicago: NTC Contemporary Publishing Company, 1998.

Dávila, Arlene. Latinos, Inc.: The Marketing of a People. Berkeley: University of California Press, 2001.

Delgado, Richard y Jean Stefancic (eds.). The Latino/a Condition: A Critical Reader. New York: New York University Press, 1998.

Duany, Jorge. Quisqueya on the Hudson: The Transnational Identity of Dominicans in Washington Heights. New York: CUNY Dominican Studies Institute, 1994.

Embry, Marcus. "The Shadow of Latinidad in U.S. Literature”. Discourse 21/3 (Fall, 1999): 77-94.

Fernández, Roberto. En la Ocho y la Doce. Boston: Houghton Mifflin, 2001. Raining Backwards. Houston: Arte Público Press, 1988.

Flores, Juan. "Pan-Latino/Trans-Latino: Puerto Ricans in The 'New Nueva York'”. From Bomba to Hip-Hop: Puerto Rican Culture and Latino Identity. New York: Columbia University Press, 2000. 141-65.

"Life Off the Hyphen: Latino Literature and Nuyorican Traditions". Mambo Montage: The Latinization of New York. Agustín Laó-Montes y Arlene Dávila, eds. New York: Columbia University Press, 2001. 185-206.

“The Latino Imaginary: Dimensions of Community and Identity”. Tropicalizations: Transcultural Representations of Latinidad. Frances Aparicio y Susana ChávezSilverman, eds. Hanover: University Press of New England, 1997. 183-93.

Flores, Lauro (ed.). The Floating Borderlands: Twenty-Five Years of U.S. Hispanic Literature. Seattle: University of Washington Press, 1998.

Gracia, Jorge J.E. y Pablo De Greiff (eds.). Hispanics/Latinos in the United States: Ethnicity, Race, and Rights. New York: Routledge, 2000.

Itzigsohn, José y Carlos Dore-Cabral. “The Manifold Character of Panethnicity: Latino Identities and Practices Among Dominicans in New York City”. Laó-Montes and Padilla, 319-35.

Kevane, Bridget and Juanita Heredia (eds.) Latina Self-Portraits: Interviews with Contemporary Women Writers. Albuquerque: University of New Mexico Press, 2000.

Knauer, Lisa Maya. “Eating in Cuban”. Mambo Montage: The Latinization of New York. Agustín Laó-Montes y Arlene Dávila, eds. New York: Columbia University Press, 2001. 425-47.

Laó-Montes, Agustín and Arlene Dávila, eds. Mambo Montage: The Latinization of New York. New York: Columbia University Press, 2001.

Latina Feminist Group (eds.). Telling To Live: Latina Feminist Testimonios. Durham: Duke University Press, 2001.

Luis, William. Dance Between Two Cultures: Latino Caribbean Literature Written in the United States. Nashville, TN: Vanderbilt University Press, 1997.

Madrid, Arturo. "Juntos y revuletos: The U.S. Latino Community at the End of the 20th Century”. The Second Annual Schomber-Moreno Lecture (April, 1996).

"Imagining the U.S. Latino Community". Keynote Address (Mount Holyoke College, October 1999). 
Mora, Pat. Borders. Houston: Arte Público Press, 1986.

Nepantla: Essays from the Land in the Middle. Albuquerque: University of New Mexico Press, 1993.

Muñoz, Elías Miguel. Brand New Memory. Houston: Arte Público Press, 1998.

Oboler, Suzanne. Ethnic Labels, Latino Lives: Identity and the Politics of (Re)Presentation in the United States. Minneapolis: University of Minnesota Press, 1995.

Ortega, Eliana y Nancy Saporta Sternbach. "At the Threshold of the Unnamed: Latina Literary Discourse in the Eighties”. Breaking Boundaries: Latina Writings and Critical Readings. Asunción Horno-Delgado et al. Amherst: University of Massachusetts Press, 1989. 2-23.

Padilla, Félix. Latino Ethnic Consciousness: The Case of Mexican Americans and Puerto Ricans in Chicago. Notre Dame, IN: University of Notre Dame Press, 1985.

Pérez Firmat, Gustavo. Next Year in Cuba. New York: Doubleday, 1995.

Poey, Delia y Virgil Suárez. Iguana Dreams: New Latino Fiction. New York: Harper Perennial, 1992.

Rebolledo, Tey Diana y Eliana Rivero (eds.). Infinite Divisions: An Anthology of Chicana Literature. Tucson: University of Arizona Press, 1993.

Rivero, Eliana. “Cubanos y cubanoamericanos: perfil y presencia en los Estados Unidos”. Discurso Literario 7/1 (1989): 81-101.

"From Immigrants to Ethnics: Cuban Women Writers in the U.S.” Breaking Boundaries: Latina Writings and Critical Readings. Asunción Horno-Delgado et al. Amherst: University of Massachusetts Press, 1989. 189-200.

"Hispanic Literature in the U.S.: Self-Image and Conflict”. International Studies in Honor of Tomás Rivera. Julián Olivares, ed. Special issue of Revista ChicanoRiqueña 13/3-4 (1985): 173-192.

Rúa, Mérida. “Colao Subjectivities: PortoMex and MexiRican Perspectives on Language and Identity”. Centro 13/2 (2001): 117-33.

Sandoval, Alberto. José Can You See: Latinos On and OffBroadway. Madison: University of Wisconsin Press, 1999.

"La identidad especular del allá y del acá: nuestra imagen puertorriqueña en cuestión”. Centro IV/2 (1992): 27-43.

Santiago, Esmeralda. Almost A Woman. New York: Vintage/Random House, 1998. "Note to the Reader". Reading Group Center. Vintage Books. Online. Ver el enlace http://www.randomhouse.com/vintage/read/puerto/santiago.html . When I Was PuertoRican. New York: Vintage Books, 1994.

Stavans, Ilan. The Hispanic Condition: Reflections on Culture and Identity in America. New York: Harper, 1996.

Zimmerman, Marc. U.S. Latino Literature: An Essay and Annotated Bibliography. Chicago: March/Abrazo Press, 1992. 